\title{
Biperiden selectively induces memory impairment in healthy volunteers : no interaction with citalopram
}

Citation for published version (APA):

Sambeth, A., Riedel, W. J., Klinkenberg, I., Kähkönen, S., \& Blokland, A. (2015). Biperiden selectively induces memory impairment in healthy volunteers : no interaction with citalopram. Psychopharmacology, 232(11), 1887-1897. https://doi.org/10.1007/s00213-014-3822-9

Document status and date:

Published: 01/01/2015

DOI:

10.1007/s00213-014-3822-9

Document Version:

Publisher's PDF, also known as Version of record

Document license:

Taverne

Please check the document version of this publication:

- A submitted manuscript is the version of the article upon submission and before peer-review. There can be important differences between the submitted version and the official published version of record.

People interested in the research are advised to contact the author for the final version of the publication, or visit the DOI to the publisher's website.

- The final author version and the galley proof are versions of the publication after peer review.

- The final published version features the final layout of the paper including the volume, issue and page numbers.

Link to publication

\footnotetext{
General rights rights.

- You may freely distribute the URL identifying the publication in the public portal. please follow below link for the End User Agreement:

www.umlib.nl/taverne-license

Take down policy

If you believe that this document breaches copyright please contact us at:

repository@maastrichtuniversity.nl

providing details and we will investigate your claim.
}

Copyright and moral rights for the publications made accessible in the public portal are retained by the authors and/or other copyright owners and it is a condition of accessing publications that users recognise and abide by the legal requirements associated with these

- Users may download and print one copy of any publication from the public portal for the purpose of private study or research.

- You may not further distribute the material or use it for any profit-making activity or commercial gain

If the publication is distributed under the terms of Article $25 \mathrm{fa}$ of the Dutch Copyright Act, indicated by the "Taverne" license above, 


\title{
Biperiden selectively induces memory impairment in healthy volunteers: no interaction with citalopram
}

\author{
Anke Sambeth • Wim J. Riedel • Inge Klinkenberg • \\ Seppo Kähkönen • Arjan Blokland
}

Received: 17 July 2014 / Accepted: 14 November 2014 / Published online: 4 December 2014

(C) Springer-Verlag Berlin Heidelberg 2014

\begin{abstract}
Rationale Traditionally, the non-selective muscarinic antagonist scopolamine has been used to induce episodic memory impairments as found in Alzheimer's disease (AD). However, it also impairs attention and induces drowsiness. Muscarinic antagonists more selective for the M1 receptor might, therefore, be preferred.

Objectives We examined the effects of the M1 antagonist biperiden on cognitive functions in order to test the specificity of this drug on memory performance. Additionally, we assessed whether the selective serotonin re-uptake inhibitor citalopram can reverse a possible biperiden-induced impairment.

Methods The study was conducted according to a doubleblind, placebo-controlled, four-way cross-over design. Sixteen volunteers received biperiden $(2 \mathrm{mg})$, citalopram $(20 \mathrm{mg})$, a combination of the two, or a placebo in counterbalanced order with a washout of at least 4 days. Cognitive tests (verbal memory, continuous recognition memory, spatial memory, choice reaction) were performed 4 and $1 \mathrm{~h}$ after treatment with citalopram and biperiden, respectively. Results Biperiden impaired memory performance in the verbal learning task, the continuous recognition memory test, and the spatial memory task. Effects on attention and side effects, as measured using the choice reaction time test and
\end{abstract}

A. Sambeth $(\bowtie) \cdot$ W. J. Riedel $\cdot$ I. Klinkenberg $\cdot$ A. Blokland Faculty of Psychology and Neuroscience, Department of Neuropsychology and Psychopharmacology, Maastricht University, Universiteitssingel 40, 6229 ER Maastricht, The Netherlands e-mail: anke.sambeth@maastrichtuniversity.nl

A. Sambeth · S. Kähkönen

BioMag Laboratory, HUS Medical Imaging Center, Helsinki

University Central Hospital, PO Box 340, Helsinki 00029, Finland questionnaires respectively, could be neglected. Citalopram did not affect any of the memory or attention measures taken. Most importantly, citalopram was also unable to reverse the biperiden-induced memory impairments.

Conclusions Our results, thus, show that the M1 antagonist biperiden may serve as a translational model to induce episodic memory deficits as seen in AD. However, the interactive influence of acetylcholine and serotonin on memory could not be confirmed.

Keywords Attention · Biperiden · Citalopram · Memory (consolidation) $\cdot \mathrm{M} 1$ antagonist $\cdot$ SSRI

\section{Introduction}

One of the earliest symptoms in Alzheimer's disease (AD) is episodic memory impairment. Current treatment for these symptoms is mainly focused on increasing cholinergic neurotransmission and with less focus on the glutamate system (Lleo et al. 2006). However, the effectiveness of current drugs such as donepezil, galantamine, rivastigmine, and memantine on memory performance has been shown to be rather limited (Lee et al. 2007; Schwarz et al. 2012). Next to acetylcholine (ACh), other neurotransmitters are dysregulated in AD as well (Rodriguez et al. 2012; Xu et al. 2012). Therefore, investigating the role of other neurotransmitter systems such as seroto$\operatorname{nin}(5-\mathrm{HT})$, which is abnormal in patients with $\mathrm{AD}$ (Rodriguez et al. 2012; Trillo et al. 2013), may be valuable. It was frequently shown that 5-HT manipulations affect memory performance in healthy volunteers (e.g., Harmer et al. 2002; Kuypers and Ramaekers 2005; Sambeth et al. 2007). This likely relates to the memory and other cognitive impairments seen in depression (for overview, see Rock et al. 2014) and to 
those induced in participants with a family history of depression (e.g., Evers et al. 2009; Klaassen et al. 2002). Due to the fact that 5-HT is dysfunctional in $\mathrm{AD}$ and depression, it was proposed that the 5-HT system could play a role in mediating ACh-related cognitive deficits (Seyedabadi et al. 2014; Steckler and Sahgal 1995; Toda et al. 2010). Assessing the interactions of 5-HT with ACh may eventually lead to a better insight into the interaction of $\mathrm{ACh}$ and 5-HT in memory processing by assessing whether possible $\mathrm{ACh}$-induced memory impairment could indeed be reversed by increasing 5 -HT levels in the brain.

In order to develop effective medication to treat memory symptoms in $\mathrm{AD}$ patients, it is important to have a good model to mimic episodic memory deficits, especially those seen during acquisition, as they are seen in AD. Scopolamine, a muscarinic antagonist, has long been used as such a model (Klinkenberg and Blokland 2010). However, due to its widespread effects on attention and several side effects (such as drowsiness), scopolamine may only partially explain the impairments found in terms of real episodic memory effects (Klinkenberg and Blokland 2010). This may partially be related to the non-selective binding of scopolamine to all five muscarinic receptors (i.e., M1-M5) both in the body and the brain. Cognitive functions such as learning and memory have often been attributed to the M1 receptor. The M1 receptor is widely expressed in brain structures related to memory, namely the cerebral cortex, hippocampus, striatum, and thalamus (Langmead et al. 2008). Therefore, a more selective M1 antagonist may be preferable as a pharmacological model for episodic memory impairments seen in $\mathrm{AD}$ than scopolamine is.

Recently, it was shown that the muscarinic M1 antagonist biperiden is capable of disrupting short-term memory performance, but not sensorimotor responding, food motivation, or attention in rats (Klinkenberg and Blokland 2011). These results are in line with the idea that biperiden is more specific in its effects on memory. Some studies in humans have been performed using M1 antagonists as well. Using a healthy elderly population, Wezenberg et al. (2005) demonstrated impairments in verbal memory, visuospatial processes, and motor learning, but not visual memory after $2 \mathrm{mg}$ of biperiden administered $1 \mathrm{~h}$ prior to the learning phase. Effects of biperiden on working memory were equivocal, and there were no indications of "sedation," which was measured using a simple and a choice reaction time test. In line with these findings, Nakra et al. (1992) reported memory deficits after the muscarinic M1 antagonist trihexyphenidyl $(2 \mathrm{mg})$ when administered before learning. Deficits were found on immediate and delayed recall of verbal and visual material in healthy elderly participants. General orientation, attentionconcentration, and learning of word associations were shown to be unaffected. In a pilot study, Pomara et al. (2004) demonstrated an association between memory impairments induced by trihexyphenidyl $(1,2 \mathrm{mg})$ and the APOE- $\varepsilon 4$ allele, which is a major genetic risk factor for AD. Specifically, total immediate recall scores as assessed with the Buschke Selective Reminding Task were affected by trihexyphenidyl in both the $\varepsilon 4$ and non- $\varepsilon 4$ carriers. Delayed recall was only impaired in the $\varepsilon 4$ carriers, mainly 2.5 and $5 \mathrm{~h}$ after drug intake. The authors concluded that $\varepsilon 4$ carriers are more vulnerable to events which impact the cholinergic system, as they recover more slowly as compared to non- $\varepsilon 4$ carriers.

In sum, previous findings using M1 antagonists have revealed that the impairments found after acute treatment with such a substance are more specifically related to (episodic) memory than what was generally found after scopolamine. However, more studies in humans, including healthy young volunteers, are needed to test the robustness of M1 antagonists as a model of episodic memory deficits. Further, the profile of the cognitive impairments after M1 blockade requires further studies. Therefore, in the current study, we examined the effects of biperiden on various types of memory, on attention, and on the side effect profile after biperiden intake. We expected that biperiden, administered $1 \mathrm{~h}$ before the acquisition phase, would induce lower immediate and delayed recall scores, and lower recognition scores on a verbal memory test. In addition, we anticipated that biperiden would not affect psychomotor performance/attention in a choice reaction time task and would not induce side effects on a self-report questionnaire.

It has long been known that, on the anatomical level, ACh and 5-HT interact (Cassel and Jeltsch 1995; Steckler and Sahgal 1995). Among others, there are serotonergic projections from the dorsal raphe (the site responsible for 5-HT release) to the basal forebrain (major cholinergic output region of the brain). Another additional important connection lies in the hippocampus, a structure highly important for memory; serotonergic neurons innervate cholinergic neurons in this brain area. Since the M1 receptor is largely present in the hippocampus and as this is one of the most important brain structures involved in memory (Langmead et al. 2008), an interaction between the cholinergic and serotonergic system on memory could be expected.

Experimental findings in animals (Cassel and Jeltsch 1995; Decker and McGaugh 1991; Stancampiano et al. 1999; Steckler and Sahgal 1995) and humans (Garcia-Alloza, et al. 2005; Little, et al. 1995) indeed suggest that ACh and 5-HT interact in their effect on cognitive functions. However, the exact nature of the ACh and 5-HT interaction related to cognition is still not entirely clear, nor is the interactive role in their effect on declarative memory. Lieben et al. (2005) recently were one of the first to examine the effects of 5-HT and $\mathrm{ACh}$ on object recognition memory in rats. They showed that a 5-HT6 antagonist was able to reverse a memory deficit caused by scopolamine (see also Woolley et al. 2003). Egashira et al. (2006) found similar results using a spatial 
memory test in rats. The selective serotonin re-uptake inhibitor (SSRI) citalopram was able to reverse a scopolamineinduced memory impairment.

In the current study, we assessed whether a memory impairment induced by biperiden could be reversed using the SSRI citalopram. We chose citalopram because it previously has improved memory consolidation in healthy young volunteers when administered IV 45 min prior to the start of memory encoding (Harmer et al. 2002) and because it showed promising results in the animal study of Egashira et al. (2006). As noted above, we expected biperiden to impair both immediate and delayed recall on a verbal learning task. Based on the animal findings, we hypothesized citalopram to reverse this impairment. No effects on the attention task were expected regarding either of the treatments, as attention was not affected by either biperiden (i.e., the sedation measures in Wezenberg et al. 2005) or citalopram (Harmer et al. 2002) in previous research.

\section{Methods}

\section{Participants}

Sixteen (seven males, nine females; mean age of 23.4 years $(\mathrm{SD}=3.2$, range $=19-31))$ right-handed healthy volunteers were recruited from the University of Helsinki through email advertisements. Participants had a body mass index of 18.5 to 30. They filled out a medical questionnaire before participation. Exclusion criteria were past or current psychiatric, neurological, cardiac, gastrointestinal, hematological, hepatic, pulmonary, or renal illness; pregnancy; lactation; excessive alcohol consumption (intake of more than 20 glasses per week); use of any medication other than oral contraceptives; having a first-degree relative with a current or past psychiatric disorder; and presence of other deficits that could be expected to influence performance. All subjects gave a signed informed consent before inclusion and were financially rewarded for their participation. The study was approved by the National Research Ethics Council of Finland, based in Helsinki.

\section{Treatment and study design}

Biperiden (Akineton ${ }^{\circledR}$, instant release) is a muscarinic M1 antagonist approved for the treatment of Parkinson symptoms which develop due to use of first-generation antipsychotics (e.g., Ogino et al. 2011). It has about 10-fold higher affinity for M1 as compared to M2-M5 receptors and it is thus the most selective M1 antagonist available for use in human participants (Bolden et al. 1992; Katayama et al. 1990). Peak plasma concentrations are reached around $1-2 \mathrm{~h}$ after a single dose administration followed by a rapid initial decline to values around $12 \%$ of the peak values at $6 \mathrm{~h}$ after intake (Hollman et al. 1984, 1987). The most common side effects of biperiden on the central nervous system are drowsiness, vertigo, headache, and dizziness. Peripheral side effects consist of blurred vision, mydriasis, dry mouth, impaired sweating, abdominal discomfort, and obstipation (e.g., Mintzer and Burns 2000; Peters 1989; Tune et al. 1992). We chose for a dose of $2 \mathrm{mg}$ as this lies well within the range of the therapeutically recommended doses for biperiden ( $1-4 \mathrm{mg}$ ). Moreover, oral treatment with $2 \mathrm{mg}$ biperiden has been shown to impair cognitive performance in healthy elderly (Wezenberg et al. 2005).

Citalopram $\left(\right.$ Cipramil $\left.^{\circledR}\right)$ is a selective serotonin reuptake inhibitor, which increases the general serotonin levels in the brain. It does so by inhibiting the reuptake of 5-HT into the pre-synapse, which causes increased 5-HT levels in the synapse. Citalopram peaks in the plasma about $4 \mathrm{~h}$ after a single does and it has a terminal half-life of around 33-35 h (Kragh Sorensen et al. 1981; Milne and Goa 1991; van Harten 1993). The most common side effects are fatigue, drowsiness, dry mouth, increased sweating, trembling, headache, dizziness, sleep disturbances, cardiac arrhythmia, blood pressure changes, nausea, diarrhea, and sexual dysfunctions in both males and females. We chose for a dose of $20 \mathrm{mg}$ as this lies well within the range of the therapeutically recommended doses for citalopram (10-40 mg).

Both biperiden and citalopram were purchased and labelled by Yliopiston Pharmacy in Helsinki according to local guidelines.

The study was conducted according to a double-blind, placebo-controlled, four-way cross-over design. The order of treatments (biperiden, citalopram, a combination, or placebo) was balanced over four test days and separated by a washout period of at least 4 days.

\section{Procedure}

After enrolment in the study, the participants first performed a training session, in which they were familiarized to the procedure and practiced all attention and memory tests.

Participants were not allowed to use any psychoactive medication within 5 days before drug intake. The volunteers where asked to abstain from alcohol on a testing day and $24 \mathrm{~h}$ before testing. They were also not allowed to smoke and were requested not to consume any caffeine-, theine- or aspartamecontaining beverages on a testing day. Participants were instructed to arrive at the laboratory well-rested. Female participants were tested in the follicular phase of the menstrual cycle.

Upon arrival, participants filled in the questionnaires (see below). Subsequently, they were given a capsule containing either a placebo or $20 \mathrm{mg}$ citalopram. During the ensuing $3 \mathrm{~h}$, the participants remained at the specially equipped laboratory room, where they could read or play board games. One hour before testing, another capsule was given containing either a 
placebo or $2 \mathrm{mg}$ biperiden. They were provided lunch immediately afterwards: this was done in order to reduce the chances of participants developing any side effects due to biperiden intake. Lunch consisted of a can of caffeine-free soda, a cup of theine free tea, or a glass of water, and one to three slices of bread and cheese, ham, or jam. Next, they were prepared for the EEG and MEG measurements. Four hours after the first treatment, the assessments started (see below). First, participants performed the immediate recall of a verbal learning task (VLT), followed by a continuous recognition memory paradigm (CRMT), an immediate recognition of a spatial memory test (SMT), and a choice reaction time test (CRT). After the CRT, delayed recall and recognition of the VLT was performed (the VRT), which was followed by a delayed recognition of the SMT. The total duration of testing was around $1.5 \mathrm{~h}$, after which the participants were asked to fill out the questionnaires again.

\section{Questionnaires}

The profile of mood states (POMS) (McNair et al. 1971) is a self-evaluation scale for short, alternating states. The POMS consists of 72 adjectives comprising five bipolar mood factors related to anger, depression, fatigue, tension, and vigor. Next to each adjective was a five-point scale. In this way, the participant could indicate in what amount these items were appropriate to his/her mood.

For each of the six mood factors, the mean score was calculated. This score was compared between the baseline (upon arrival in the lab) and the test (after the assessments), to examine whether the treatments changed mood.

Neurovegetative effects, using 31 items such as headache, nausea, and sleepiness, were registered. Next to each adjective was a five-point scale in order for participants to indicate in what amount they experienced these symptoms.

\section{Verbal learning task}

This task is an adapted version of Rey's Auditory Verbal Learning Test (Lezak 1995) and is one of the mostly used memory paradigms in psychopharmacology. The VLT was used to measure declarative memory (Riedel et al. 1999). The test consisted of a list of 30 monosyllabic English words that were presented on a computer screen (stimulus presentation time was 1,000 ms and inter-stimulus interval 2,000 ms). This presentation was repeated three times using the same sequence of words, each time followed by immediate free recall of all remembered words. Forty-five minutes after immediate free recall of the final series, participants were subjected to a delayed recall test and a yes/no recognition test (VRT). During the latter, 60 words were presented: 30 of which were previously presented and another 30 that were new. The words remained on the screen for 1,500 ms. Another
1,500 ms elapsed before the next words appeared on the screen. After presentation of each word, the participant had to respond as fast as possible to indicate recognition of the word by pressing a button with the right index finger for "old" and by pressing a button with the right ring finger for "new" stimuli.

Outcome measures were number of correctly recalled words during each of the three immediate recall trials and number of correctly recalled words during delayed recall tests. The behavioral-dependent measures of the recognition test were median reaction time, measured in milliseconds and the number of correctly recognized old and new words.

In each of the assessments, a different word list was presented. The lists were comparable with regard to level of abstraction and affective tone of the words. All participants received the same practice list. The order of the four parallel lists used for testing was balanced across assessments.

Continuous recognition memory task

This task assesses recognition memory and can be seen as a model of time-dependent forgetting. In the task, a series of pictures (black and white line drawings) were presented on a computer screen with a duration of $800 \mathrm{~ms}$ and an interstimulus interval of $3,000 \mathrm{~ms}$. The task started by randomly presenting four control pictures ten times each. Next, the experimental pictures were shown. Sixty pictures were repeated once in the series, divided into three sets. A set of 20 pictures reoccurred either 2, 4 , or 11 pictures after the first occurrence of the picture (see also Curran et al. 1998; Van Strien et al. 2007). The control pictures that were shown in the very beginning were used as fillers. The participants' task was to rate each of the pictures as "old" or "new" by pressing a button with the right index and right ring finger, respectively, according to whether they were presented for the first time or whether it was a repetition.

The outcome measures were the number of correct detections, misses, and false alarms. Furthermore, the reaction times were assessed.

\section{Spatial memory test}

The SMT is a spatial memory task (based on the object relocation test (Kessels et al. 1999; Sambeth et al. 2009) that consisted of two parts: immediate and delayed recognition. The immediate recognition comprised six trials in which ten pictures (total of 60 pictures) were presented one by one on a computer screen (encoding phase) with a duration of $2,000 \mathrm{~ms}$ and inter-stimulus interval of $1,000 \mathrm{~ms}$. The participants had to remember the location of the pictures. After each trial, the objects disappeared from the screen and reappeared one by one in the middle of the screen (repetition phase) for $2,000 \mathrm{~ms}$, followed by the presentation of a " 1 " and a " 2 " in different 
locations (relocation phase) for 1,200 ms. The participants had to determine whether the picture had been presented on the location indicated by 1 or 2 consecutively for each picture by pressing a button with right index finger for " 1 " and right ring finger for "2." During the delayed recognition procedure $45 \mathrm{~min}$ after the initial presentation of the pictures, the participant had to decide again what the location of the pictures had been. Different versions of this test were balanced over test days.

The measures used were the reaction time and the number of correct responses.

\section{Choice reaction time task}

This task assesses general alertness, motor speed, and attention and was used to assess whether the drugs administered in the current experiment affected attention/vigilance. Participants were presented with an arrow that was either shown on the left or on the right side of the screen. There were two kinds of arrows: one pointing to the left (left arrow), the other pointing to the right (right arrow). If the participant saw the left arrow, he/she had to press a button with the right index finger. If the right arrow is presented, the participant had to press a button with the right ring finger. Both arrows were presented either on the left or on the right side of the screen. Therefore, there were four stimulus sets: (1) left arrow presented on the left side (i.e., congruent left), (2) left arrow presented on the right side (incongruent left), (3) right arrow presented on the right side (congruent right), and (4) right arrow presented on the left side (incongruent right). Forty stimuli of each category were presented. The duration of stimulus presentation was $600 \mathrm{~ms}$, followed by an interstimulus interval of randomly 2,000-3,000 ms.

Outcome measures were reaction time and number of commission errors for each of the four stimulus types.

\section{Data analysis}

Data were analyzed using a repeated-measures analysis of variance (ANOVA). The treatments biperiden (biperiden or placebo) and citalopram (citalopram or placebo) were used as separate within-subject factor. Separate analyses were performed for accuracy and reaction times.

For the VLT, the following additional within-subjects factors were used: trial (1-3) was added for the immediate recall and stimulus type (old vs. new) was used for the recognition test. For the CRMT, delay (number of items between encoding and recognition, thus 1,3 , or 10) and stimulus type (old vs. new) were additionally used for analysis. With regard to the SMT, the additional with-subjects factor was delay (immediate vs. delayed recognition). For the CRT, congruency (congruent vs. incongruent) and arrow (pointing to right vs. to left) were additional within-subjects factors.
Adverse effects and the mood scales were also analyzed using an ANOVA. For this analysis, differences between effects at test vs. at baseline were taken into account. The level of significance was set at 0.05 throughout and post-hoc testing was performed with a least significant difference (LSD) test.

\section{Results}

Missing data

Two participants had issues pressing buttons with their right ring finger during memory paradigms and the responses were not always recorded. Therefore, the data of those two participants were excluded from all analyses in which responses had to be made by button press. In the CRT task, no missing values were seen and all participants were included. Additionally, the data were scrutinized for outliers.

\section{VLT}

Results for all 16 participants were analyzed. Recall significantly increased from trial 1 to trial 2 to trial 3 during encoding $(F(2,30)=635.63, p<0.001)$. Additionally, a main effect of biperiden was found for the immediate recall $(F(1,15)=$ 22.66, $p<0.001)$. Participants significantly recalled fewer words after biperiden than after placebo or citalopram (see the total recall of the three trials in Fig. 1a and Table 1). Citalopram did not affect immediate recall $(F(2,30)=0.36$, n.s.) nor did we find any significant interactions between drug treatments $(F$ values $<1.31)$.

As for the delayed recall, the same effect was found. Participants recalled fewer words after biperiden $(F(1,15)=$ $24.29, p<0.001)$ but no main effect of citalopram or interaction between the two treatments was found $(F$ values $<0.15)$, see Fig. $1 \mathrm{~b}$ and Table 1.

\section{VRT}

In addition to the two subjects that did not press the response button reliably, two participants were detected as outliers. Therefore, the analysis was performed on 12 participants only. The median reaction time in the recognition paradigm did not change after any of the treatments, nor was any significant interaction found. However, participants responded faster to old than to new words $(F(1,11)=17.10, p<0.003)$. With regard to the correct detections of old and new words, participants recognized fewer old and new words after biperiden as compared to placebo $(F(1,11)=7.77, p<0.036)$, see Table 1 . 
Fig. 1 a Total number of words recalled during the three immediate recall trials after each of the four treatments; $\mathbf{b}$ number of words recalled during delayed recall after each of the four treatments. For both immediate and delayed recall, biperiden impaired memory performance, which was not reversed by citalopram in the combined treatment condition a Immediate recall

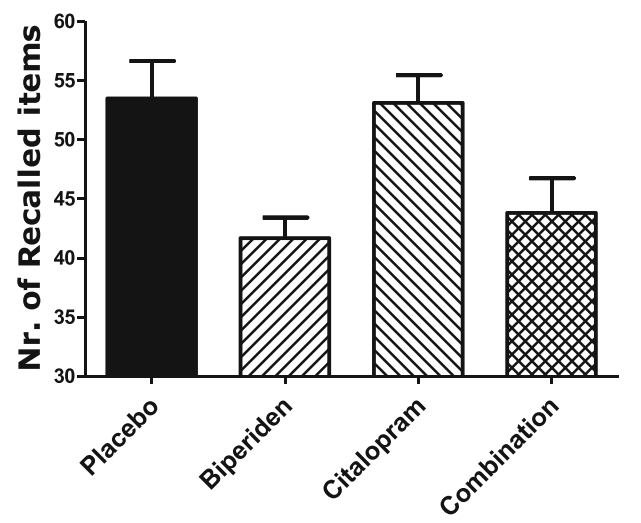

b Delayed recall

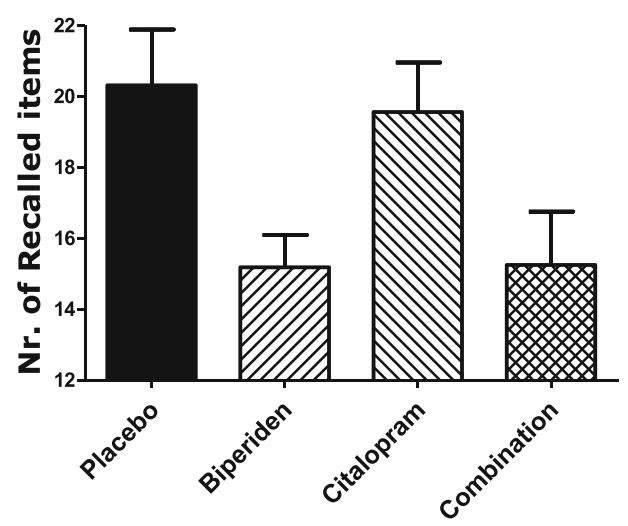

\section{CRMT}

One outlier was detected and, therefore, analysis was performed on 13 participants. Accuracy was higher for new than for old stimuli $(F(1,12)=4.92, p<0.048)$. Additionally, biperiden impaired accuracy on this test as compared to placebo $(F(1,12)=7.44, p<0.019)$, see Table 1 . No other main effects or interactions were found related to accuracy for this paradigm $(F$ values $<2.08)$.

With regard to the reaction times, participants responded faster to old than to new stimuli $(F(1,12)=12.92, p<0.005)$. Biperiden slowed reaction times as compared to placebo $(F(1,12)=4.98, p<0.047)$. None of the other main or interaction effects reached significance ( $F$ values $<2.79$ ).

\section{SMT}

Biperiden impaired accuracy during the SMT as compared to placebo $(F(1,13)=4.75, p<0.049)$. Furthermore, there was a main effect of delay (immediate vs. delayed recognition) $(F(1,13)=57.75, p<0.001)$, indicating that participants performed much better during immediate than during delayed recognition. Also, a significant interaction between citalopram and delay was found $(F(1,13)=6.49, p<0.025)$. Post-hoc analysis for each of the two delays separately did not show any significant effects of citalopram. But this analysis showed that the biperiden impairment found was mainly due to the delayed recognition rather than immediate $(p<0.045$ for delayed vs. $p<0.149$ for immediate), see Fig. 2 and Table 1.

Table 1 Mean scores (standard errors, SE) for the outcome variables of the verbal learning task, verbal recognition task, continuous recognition memory test, spatial memory task, and choice reaction time task

\begin{tabular}{|c|c|c|c|c|}
\hline & Placebo & Biperiden & Citalopram & Combination \\
\hline \multicolumn{5}{|l|}{ Verbal learning task (VLT) } \\
\hline Immediate recall: mean recall per trial & $17.83(1.05)$ & $13.90(0.58)^{* *}$ & $17.71(0.78)$ & $14.60(0.98)^{* *}$ \\
\hline Delayed recall & $20.31(1.57)$ & $15.19(0.91)^{* *}$ & $19.56(1.39)$ & $15.25(1.50)^{* *}$ \\
\hline \multicolumn{5}{|l|}{ Verbal recognition task (VRT) } \\
\hline $\begin{array}{l}\text { Number of words correctly recognized (average of old } \\
\text { and new words) }\end{array}$ & $27.25(0.72)$ & $25.42(1.13)^{*}$ & $26.38(1.07)$ & $25.75(0.94)^{*}$ \\
\hline $\begin{array}{l}\text { Median reaction time for correct responses to old and } \\
\text { new stimuli (in ms) }\end{array}$ & $747(42)$ & $800(44)$ & $759(35)$ & $797(39)$ \\
\hline \multicolumn{5}{|l|}{ Continuous recognition memory test (CRMT) } \\
\hline Correct responses (average of old/new and delay $1 / 3 / 10$ ) & $17.97(0.84)$ & $16.50(1.21)^{*}$ & $17.89(0.89)$ & $16.72(1.12)^{*}$ \\
\hline Reaction time for correct responses (in ms) & $739(32)$ & $798(43)^{*}$ & $712(36)$ & $777(33)^{*}$ \\
\hline \multicolumn{5}{|l|}{ Spatial memory task (SMT) } \\
\hline Correct responses for immediate recognition & $47.43(1.67)$ & $47.07(1.81)$ & $50.50(1.55)$ & $47.71(2.21)$ \\
\hline Correct responses for delayed recognition & $45.43(1.17)$ & $42.14(1.61)^{*}$ & $44.21(1.73)$ & $41.21(2.35)^{*}$ \\
\hline $\begin{array}{l}\text { Mean reaction time for correct responses (in ms) during } \\
\text { immediate and delayed recognition }\end{array}$ & $757(32)$ & $785(32)$ & $713(35)$ & $828(36)$ \\
\hline \multicolumn{5}{|l|}{ Choice reaction time test (CRT) } \\
\hline Commission errors & $0.92(0.27)$ & $3.68(1.61)$ & $1.36(0.51)$ & $2.85(1.22)$ \\
\hline Reaction time for correct responses (in ms) & $519(25)$ & $530(23)$ & $526(33)$ & $552(32)$ \\
\hline
\end{tabular}

${ }^{*} p<0.05 ;{ }^{*} p<0.001$ (Of note, asterisks are shown for both biperiden and combination because they together reflect the main effect of biperiden) 
Fig. 2 a Total number of pictures correctly located during the immediate recognition trials after each of the four treatments; $\mathbf{b}$ number of pictures correctly located during delayed recognition after each of the four treatments. It can be seen that biperiden impaired performance in the delayed recognition phase
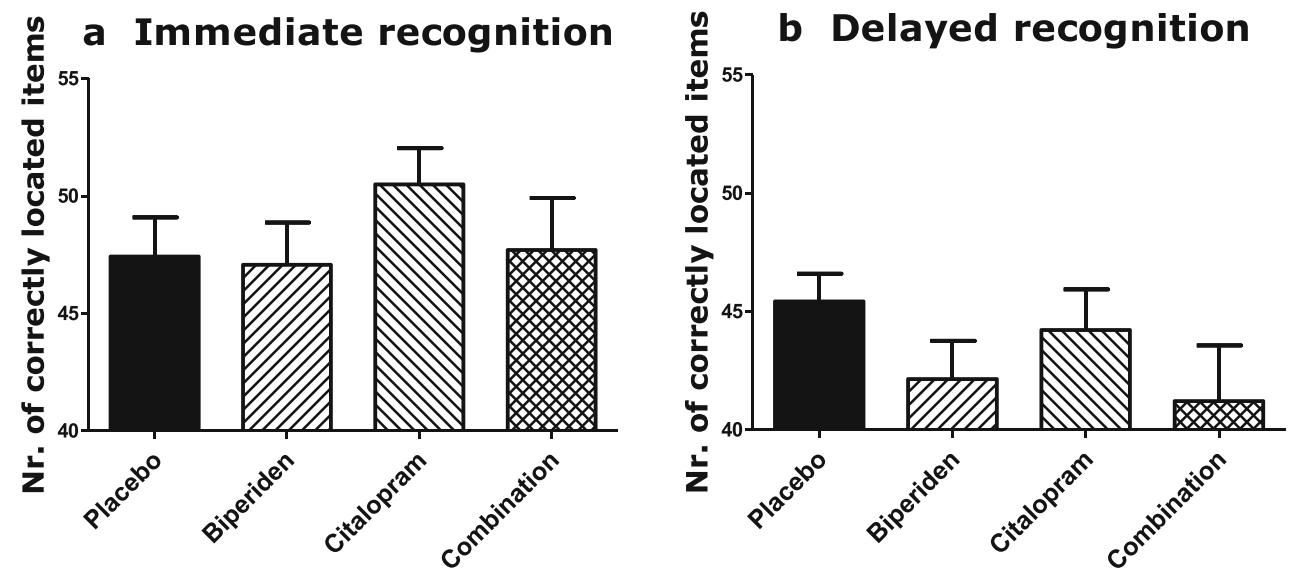

Neither treatment, nor delay, affected reaction time $\left(F_{\mathbf{S}}<\right.$ 3.30).

\section{CRT}

Data from one participant was excluded because (s)he was an outlier. Therefore, results from 15 volunteers were analyzed. With regard to the commission errors, no significant main or interaction effects regarding any of the treatments were found, although biperiden marginally impaired performance $(F(1,14)=4.251, p<0.059)$, see Table 1 . The participants made less mistakes to congruent than to incongruent trials, $F(1,14)=9.02, p<0.01$ (main effect of congruency), which was caused mainly by the arrows pointing to the left $(F(1,14)=7.69, p<0.016$; interaction between congruency and arrow type).

Neither of the treatments affected reaction times during this test nor was any significant interaction with treatment found ( $F$ values $<2.26)$. A main effect of congruency was found $(F(1,14)=15.56, p<0.002)$. Participants responded faster to congruent than incongruent stimuli. Additionally, the factor arrow reached significance $(F(1,14)=14.35, p<0.003)$ which was caused by the fact that participants responded quicker to arrows pointing to the right as compared to arrows pointing to the left (thus when pressing a button with their right as compared to their left hand).

\section{Mood scale and neurovegetative effects}

Tension was marginally decreased after biperiden treatment as compared to placebo $(F(1,15)=4.202, p<0.059)$, see Table 2 . An interaction was found between biperiden and citalopram regarding the factor aggression $(F(1,15)=6.106, p<0.027)$. This effect was caused by the fact that biperiden and citalopram treatment alone seemed to decrease aggression to some extent, whereas this decrease was absent in the combined treatment condition. For the factor fatigue, a similar interaction was found $(F(1,15)=5.581, p<0.033)$. Whereas both biperiden and citalopram when administered alone slightly reduced fatigue as compared to placebo, the combined treatment did not reveal such an effect.

As for the neurovegetative effects (see the most common ones in Table 2), participants reported a significant increase in having a dry mouth after biperiden as compared to placebo $(F(1,15)=8.14, p<0.013)$. Neither of the other aspects was affected by any of the treatments, nor were interactions between biperiden and citalopram found.

\section{Discussion}

In this study, we examined the effects of biperiden on cognitive functions in order to test the specificity of this drug on

Table 2 Mean difference scores as change from baseline (standard errors, SE) for the questionnaire data. Negative numbers indicate a decrease and positive numbers indicate an increase in the feeling

\begin{tabular}{lllll}
\hline & Placebo & Biperiden & Citalopram & Combination \\
\hline $\begin{array}{l}\text { Profile of mood states } \\
\text { Depression }\end{array}$ & $1.69(1.50)$ & $1.19(1.40)$ & $1.56(0.58)$ & $2.06(1.22)$ \\
Tension & $0.56(0.55)$ & $-0.94(0.80)$ & $1.00(0.52)$ & $0.19(0.64)$ \\
Aggression & $-0.25(0.39)$ & $-0.37(0.22)$ & $-0.63(3.97)$ & $0.37(0.52)$ \\
Fatigue & $1.94(0.64)$ & $1.19(0.44)$ & $0.56(0.45)$ & $1.81(0.66)$ \\
Vigor & $2.94(1.11)$ & $3.56(0.97)$ & $2.06(0.93)$ & $4.06(1.10)$ \\
Neurovegetative effects & & & \\
Dry mouth & $0.31(0.20)$ & $0.75(0.23)$ & $0.13(0.20)$ & $1.06(0.32)$ \\
Sleepiness & $0.81(0.23)$ & $0.44(0.26)$ & $0.25(0.21)$ & $0.75(0.32)$ \\
Nausea & $-0.06(0.11)$ & $0.13(0.09)$ & $0.19(0.16)$ & $0.44(0.29)$ \\
Headache & $0.37(0.22)$ & $0.00(0.16)$ & $0.00(0.09)$ & $0.00(0.13)$ \\
Dizziness & $0.37(0.18)$ & $0.31(0.12)$ & $0.44(0.16)$ & $0.50(0.22)$ \\
Fatigue & $0.25(0.14)$ & $0.37(0.16)$ & $0.25(0.14)$ & $0.31(0.15)$ \\
Drowsiness & $0.38(0.20)$ & $0.31(0.18)$ & $0.44(0.23)$ & $0.56(0.18)$ \\
\hline
\end{tabular}


memory performance. Additionally, considering the interactions between ACh and 5-HT that have been shown on cognition in animal work, we assessed to which extent the SSRI citalopram can reverse this impairment. We showed that biperiden indeed impaired memory performance in different tasks, whereas the effects on attention and side effects could be neglected. Citalopram did not affect any of the memory or attention measures taken. Most importantly, citalopram was also unable to reverse the biperiden-induced memory impairments we found.

Our findings regarding the biperiden-induced memory impairment are in line with those found in the literature on memory-impairing effects of muscarinic antagonists in humans (e.g., Atri et al. 2004; Bishop et al. 1996; Broks et al. 1988; Crow et al. 1975; Drachman and Leavitt 1974; Frith et al. 1984; Green et al. 2005; Kamboj and Curran 2006; Kopelman and Corn 1988; Mintzer and Griffiths 2003, 2005, 2007; Nakra et al. 1992; Pomara et al. 2004; Rasch et al. 2006; Robbins et al. 1997; Sherman et al. 2003; Snyder et al. 2005; Sperling et al. 2002; van Ruitenbeek et al. 2008; Wezenberg et al. 2005). Specifically, the current results successfully replicated the findings of Wezenberg et al. (2005) who also showed impairments in immediate and delayed recall and recognition of verbal material in elderly volunteers. Additionally, cognition-impairing effects of muscarinic M1 antagonists generally do not seem to be specific for any particular memory system or sensory modality, as they have been found to influence not only verbal but also visual, spatial, short-term, and working memory, exactly what we found in this experiment as well (e.g., Nakra et al. 1992; Wezenberg et al. 2005).

The role of the muscarinic M1 receptor in attention is unclear at present. For instance, Wezenberg et al. (2005) reported that $2 \mathrm{mg}$ of biperiden impaired movement time in a motor learning task, which was interpreted as an attentional effect rather than a slowing of psychomotor performance. In addition, biperiden also appeared to disrupt visuospatial processes, but these effects were not as strong and robust relative to those in the memory tasks. In contrast, Nakra et al. (1992) reported no effect of the muscarinic M1 antagonist trihexyphenidyl $(2 \mathrm{mg})$ on attention-concentration measures in the Wechsler Memory Scale. In line with the latter finding, we recently reported a lack of effects of biperiden on accuracy performance in a visual target detection task assessing learned irrelevance processes (Klinkenberg et al. 2012). In the current study, a marginally significant increase in commission errors was found during the attentional CRT test. This might imply a minor role for the M1 receptor in attention. But, this effect is relatively small as compared to the effect on memory performance, which was affected in each single memory test used in the current study. Taken together, the M1 receptor does not appear to play a major role in attentional processes.
In the current study, we only found minor evidence of psychomotor slowing after biperiden. Response times were slowed after biperiden in the CRMT and a non-significant increase in RT could also be seen during the SMT (see Table 1). Response times, on the other hand, were not even slightly affected in the VRT or CRT test. This rather indicates that memory-related thinking time was increased and not psychomotor functioning per se. In line with this, Wezenberg et al. (2005) reported increased RTs in a shortterm memory test, which could have been a mnemonic effect. A recent study by our lab which investigated the effects of biperiden on learned irrelevance showed that RTs were increased after biperiden relative to placebo (Klinkenberg et al. 2012). It is unclear whether this effect is due to blockade of central or peripheral muscarinic M1 receptors; i.e., whether biperiden induced a global decrease in task performance and/ or psychomotor slowing.

The side effects we observed in this experiment were very mild. Whereas scopolamine has often led to drowsiness and fatigue, dizziness, a dry mouth, and to a lesser extent also discontentedness (e.g., Curran et al. 1998; Kamboj and Curran 2006; Lenz et al. 2012), we only showed that participants had a dry mouth after biperiden intake. Additionally, both biperiden and citalopram even slightly reduced aggression and fatigue. Our results are in correspondence to previous work in which also no significant side effects of M1 antagonists were seen (Nakra et al. 1992; Klinkenberg et al. 2012). Interestingly, no correlations were found between the memory and "neurovegetative" measures (data not shown). This again supports a relatively specific effect of biperiden on memory performance and strengthens our notion that a M1 receptor antagonist has a better side effect profile as compared to scopolamine.

Next to assessing the efficacy of biperiden as a model to induce memory impairments as seen in $\mathrm{AD}$, we examined the relationship between ACh and 5-HT in their role in memory. First of all, 5-HT is suggested to contribute to cognitive impairments seen in AD (for review, see Rodriguez et al. 2012), probably because ACh and 5-HT neurons interact in structures relevant for learning and memory, such as the hippocampus (e.g., Jeltsch-David et al. 2008; Steckler and Sahgal 1995). Therefore, Little et al. (1995) assessed the effects of m-chlorophenylpiperazine (m-CPP), a 5-HT mixed agonist/antagonist that has affinity for various 5-HT receptors, on scopolamine-induced memory impairment in healthy young volunteers. They found that cognitive impairments due to scopolamine were partly increased by $\mathrm{m}$-CPP treatment, indicating that $\mathrm{ACh}$ and 5-HT centrally interact, rather than only peripherally. Brooks et al. (1998), however, failed to show the same finding when administering both scopolamine and $\mathrm{m}$-CPP, although scopolamine did impair memory performance. Garcia-Alloza et al. (2005) on the other hand showed that an imbalance between the ACh and 5-HT system seen 
postmortem significantly correlated with a final mini mental state examination for cognitive impairment in patients with $\mathrm{AD}$, thus presenting evidence for an interaction between $\mathrm{ACh}$ and 5-HT in their effect on memory, at least in AD. In the current study, the only interactions we found between biperiden and citalopram were related to the mood questionnaire. Decrements in aggression and fatigue, found after single manipulations with biperiden and citalopram, were reversed after combined treatment. However, citalopram was not able to reverse any of the memory impairments we found after biperiden treatment.

The lack of an interaction between the cholinergic and serotonergic treatments with regard to cognition could be explained by various factors. First of all, the citalopram dose used, $20 \mathrm{mg}$ orally, might have been too low to improve memory. A dose of $10 \mathrm{mg}$ administered IV, which causes faster absorption as compared to our oral administration, has however been shown to improve delayed recall in a verbal learning task (Harmer et al. 2002). Additionally, we did see interactions on some of the more "behavioral" measures, namely the aggression and fatigue scales. Therefore, these findings suggest a central effect of citalopram in the present study. Another aspect may be that behavioral responses such as accuracy and reaction times are not sensitive enough to pick up the interactive effects biperiden and citalopram may have. Future research should, therefore, also focus on measures more sensitive to detect pharmacological changes, namely imaging studies such as fMRI or EEG/MEG, to study the interaction between ACh and 5-HT. Finally, it could be argued that the interaction between biperiden and citalopram cannot be found with the tests used in the present study. This does not exclude that ACh and 5-HT interact in their effect on memory. Rather, it is possible that serotonergic manipulations more specific to certain 5-HT receptor types should be administered in combination with biperiden to reveal the interactions that are in place, a procedure that is more similar to the animal work that previously was done (e.g., Lieben et al. 2005). Conversely, the selectivity for the M1 receptor of biperiden may also be related to the lack of interaction between the citalopram and biperiden in the current study, even though the M1 receptor is largely present in the hippocampus and is one of the most important memory areas in the brain (Langmead et al. 2008).

In sum, biperiden is capable of impairing memory rather selectively, i.e., without inducing peripheral side effects which could adversely affect performance and without clear effects on attention. Muscarinic M1 antagonists might, therefore, serve as a translational model for inducing selective episodic mnemonic deficits as seen in neuropsychiatric disorders, particularly AD. Interactions between biperiden and citalopram were not found, which indicates that ACh and 5-HT either do not interact in their effects on cognition, or that our measures were not sensitive enough to pick up the effects.
Acknowledgments We would like to thank Eini Knuutinen for her assistance in data acquisition. This study was sponsored by the Netherlands Organization for Scientific Research, grant number 451-07-011.

Conflict of interest Wim J. Riedel was also employed by Cambridge Cognition Ltd., Cambridge, UK, while remaining affiliated to Maastricht University, during the last few years. This raises no conflict of interest. There were no commercial or financial relationships that could be construed as a potential conflict of interest.

\section{References}

Atri A, Sherman S, Norman KA, Kirchhoff BA, Nicolas MM, Greicius MD, Cramer SC, Breiter HC, Hasselmo ME, Stern CE (2004) Blockade of central cholinergic receptors impairs new learning and increases proactive interference in a word paired-associate memory task. Behav Neurosci 118:223-236

Bishop KI, Curran HV, Lader M (1996) Do scopolamine and lorazepam have dissociable effects on human memory systems? A dose-response study with normal volunteers. Exp Clin Psychopharmacol 4: 292-299

Bolden C, Cusack B, Richelson E (1992) Antagonism by antimuscarinic and neuroleptic compounds at the five cloned human muscarinic cholinergic receptors expressed in Chinese hamster ovary cells. J Pharmacol Exp Ther 260:576-580

Broks P, Preston GC, Traub M, Poppleton P, Ward C, Stahl SM (1988) Modelling dementia: effects of scopolamine on memory and attention. Neuropsychologia 26:685-700

Brooks A, Little JT, Martin A, Minichiello MD, Dubbert B, Mack C, Tune L, Murphy DL, Sunderland T (1998) The influence of ondansetron and $\mathrm{m}$-chlorophenylpiperazine on scopolamineinduced cognitive, behavioral, and physiological responses in young healthy controls. Biol Psychiatry 43:408-416

Cassel JC, Jeltsch H (1995) Serotonergic modulation of cholinergic function in the central nervous system: cognitive implications. Neuroscience 69:1-41

Crow TJ, Grove-White I, Ross DG (1975) The specificity of the action of hyoscine on human learning. P Brit Pharmacol Soc 368P:24-25

Curran HV, Pooviboonsuk P, Dalton JA, Lader MH (1998) Differentiating the effects of centrally acting drugs on arousal and memory: an event-related potential study of scopolamine, lorazepam and diphenhydramine. Psychopharmacology (Berl) 135:27-36

Decker MW, McGaugh JL (1991) The role of interactions between the cholinergic system and other neuromodulatory systems in learning and memory. Synapse 7:151-168

Drachman DA, Leavitt J (1974) Human memory and the cholinergic system. A relationship to aging? Arch Neurol 30:113-121

Egashira N, Matsumoto Y, Mishima K, Iwasaki K, Fujioka M, Matsushita M, Shoyama Y, Nishimura R, Fujiwara M (2006) Low dose citalopram reverses memory impairment and electroconvulsive shock-induced immobilization. Pharmacol Biochem Behav 83: 161-167

Evers EAT, van der Veen FM, Jolles J, Deutz NEP, Schmitt JAJ (2009) The effect of acute tryptophan depletion on performance and the BOLD response during a Stroop task in healthy first-degree relatives of patients with unipolar depression. Psychiatr Res 173:52-58

Frith CD, Richardson JTE, Samuel M, Crow TJ, McKenna PJ (1984) The effects of intravenous diazepam and hyoscine upon human memory. Q J Exp Psychol A 36:133-144

Garcia-Alloza M, Gil-Bea FJ, Diez-Ariza M, Chen CP, Francis PT, Lasheras B, Ramirez MJ (2005) Cholinergic-serotonergic imbalance contributes to cognitive and behavioral symptoms in Alzheimer's disease. Neuropsychologia 43:442-449 
Green A, Ellis KA, Ellis J, Bartholomeusz CF, Ilic S, Croft RJ, Phan KL, Nathan PJ (2005) Muscarinic and nicotinic receptor modulation of object and spatial n-back working memory in humans. Pharmacol Biochem Behav 81:575-584

Harmer CJ, Bhagwagar Z, Cowen PJ, Goodwin GM (2002) Acute administration of citalopram facilitates memory consolidation in healthy volunteers. Psychopharmacology (Berl) 163:106-110

Hollman M, Brode E, Greger G, Müller-Peltzer H, Wetzelsberger N (1984) Biperiden effects and plasma levels in volunteers. Eur J Clin Pharmacol 27:619-621

Hollman M, Müller-Peltzer H, Greger G, Brode E, Peruca E, Grimaldi R, Crema A (1987) Pharmacokinetic-dynamic study on different oral biperiden formulations in volunteers. Pharmacopsychiatry 20:72-77

Jeltsch-David H, Koenig J, Cassel JC (2008) Modulation of cholinergic functions by serotonin and possible implications in memory: general data and focus on 5-HT(1A) receptors of the medial septum. Behav Brain Res 195:86-97

Kamboj SK, Curran HV (2006) Neutral and emotional episodic memory: global impairment after lorazepam or scopolamine. Psychopharmacology (Berl) 188:482-488

Katayama S, Ishizaki F, Yamamura Y, Khoriyama T, Kito S (1990) Effects of anticholinergic antiparkinsonian drugs on binding of muscarinic receptor subtypes in rat brain. Res Commun Chem Pathol Pharmacol 69:261-270

Kessels RP, Postma A, de Haan EH (1999) Object Relocation: a program for setting up, running, and analyzing experiments on memory for object locations. Behav Res Methods Instrum Comput 31:423-428

Klaassen T, Riedel WJ, Deutz NE, Van Praag HM (2002) Mood congruent memory bias induced by tryptophan. Psychol Med 32:167-172

Klinkenberg I, Blokland A (2010) The validity of scopolamine as a pharmacological model for cognitive impairment: a review of animal behavioral studies. Neurosci Biobehav Rev 34:1307-1350

Klinkenberg I, Blokland A (2011) A comparison of scopolamine and biperiden as a rodent model for cholinergic cognitive impairment. Psychopharmacology (Berl) 215:549-566

Klinkenberg I, Blokland A, Riedel WJ, Sambeth A (2012) Human electrophysiological correlates of learned irrelevance: effects of the muscarinic M1 antagonist biperiden. Int J Neuropsychopharmacol 15:1375-1385

Kopelman MD, Corn TH (1988) Cholinergic 'blockade' as a model for cholinergic depletion. A comparison of the memory deficit with those of Alzheimer-type dementia and the alcoholic Korsakoff syndrome. Brain 111:1079-1110

Kragh Sorensen P, Overo KF, Petersen OL, Jensen K, Parnas W (1981) The kinetics of citalopram: single and multiple dose studies in man. Acta Pharmacol Toxicol (Copenh) 48:53-60

Kuypers KP, Ramaekers JG (2005) Transient memory impairment after acute dose of $75 \mathrm{mg}$ 3.4-methylene-dixymethamphetamine. J Psychopharmacol 19:633-639

Langmead CJ, Watson J, Reavill C (2008) Muscarinic acetylcholine receptors and CNS drug targets. Pharmacol Ther 117:232-243

Lee J, Monette J, Sourial N, Monette M, Bergman H (2007) The use of a cholinesterase inhibitor review committee in long-term care. J Am Med Dir Assoc 8:243-247

Lenz RA, Baker FD, Locke C, Rueter LE, Mohler EG, Wesnes K, AbiSaab W, Saltarelli MD (2012) The scopolamine model as a pharmacological marker in early drug development. Psychopharmacology (Berl) 220:97-107

Lezak M (1995) Neuropsychological assessment, 3rd edn. Oxford University Press, Oxford

Lieben CK, Blokland A, Sik A, Sung E, Van Nieuwenhuizen P, Schreiber $\mathrm{R}$ (2005) The selective 5-HT6 receptor antagonist Ro4368554 restores memory performance in cholinergic and serotonergic models of memory deficiency in the rat. Neuropsychopharmacology 30: 2169-2179
Little JT, Brooks A, Martin A, Hill JL, Tune LE, Mack C, Cantillon M, Molchan S, Murphy DL, Sunderland T (1995) Serotonergic modulation of anticholinergic effects on cognition and behavior in elderly humans. Psychopharmacology (Berl) 120:280-288

Lleo A, Greenberg SM, Growdon JH (2006) Current pharmacotherapy for Alzheimer's disease. Ann Rev Med 57:513-533

McNair DM, Lorr M, Droppleman LF (1971) Manual for the profile of mood states. San Diego, CA: Educational and Industrial Testing Service

Milne RJ, Goa KL (1991) Citalopram. A review of its pharmacodynamic and pharmacokinetic properties, and therapeutic potential in depressive illness. Drugs 41:450-477

Mintzer J, Burns A (2000) Anticholinergic side-effects of drugs in elderly people. J Roy Soc Med 93:457-462

Mintzer MZ, Griffiths RR (2003) Lorazepam and scopolamine: a singledose comparison of effects on human memory and attentional processes. Exp Clin Psychopharmacol 11:56-72

Mintzer MZ, Griffiths RR (2005) Drugs, memory, and metamemory: a dose-effect study with lorazepam and scopolamine. Exp Clin Psychopharmacol 13:336-347

Mintzer MZ, Griffiths RR (2007) Differential effects of scopolamine and lorazepam on working memory maintenance versus manipulation processes. Cogn Affect Behav Neurosci 7:120-129

Nakra BR, Margolis RB, Gfeller JD, Grossberg GT, Sata LS (1992) The effect of a single low dose of trihexyphenidyl on memory functioning in the healthy elderly. Int Psychogeriatr 4:207-214

Ogino S, Miyamoto S, Tenjin T, Kitajima R, Ojima K, Miyake N, Funamoto Y, Arai J, Tsukahara S, Ito Y, Tadokoro M, Anai K, Tatsunami S, Kubota H, Kaneda Y, Yamaguchi N (2011) Effects of discontinuation of long-term biperiden use on cognitive function and quality of life in schizophrenia. Prog Neuro-Psychopharmacol Biol Psychiatr 35:78-83

Peters NL (1989) Snipping the thread of life. Antimuscarinic side-effects of medications in the elderly. Arch Intern Med 149:2414-2420

Pomara N, Willoughby LM, Wesnes K, Sidtis JJ (2004) Increased anticholinergic challenge-induced memory impairment associated with the APOE-epsilon4 allele in the elderly: a controlled pilot study. Neuropsychopharmacology 29:403-409

Rasch BH, Born J, Gais S (2006) Combined blockade of cholinergic receptors shifts the brain from stimulus encoding to memory consolidation. J Cogn Neurosci 18:793-802

Riedel WJ, Klaassen T, Deutz NE, van Someren A, van Praag HM (1999) Tryptophan depletion in normal volunteers produces selective impairment in memory consolidation. Psychopharmacology (Berl) 141:362-369

Robbins TW, Semple J, Kumar R, Truman MI, Shorter J, Ferraro A, Fox B, McKay G, Matthews K (1997) Effects of scopolamine on delayedmatching-to-sample and paired associates tests of visual memory and learning in human subjects: comparison with diazepam and implications for dementia. Psychopharmacology (Berl) 134:95-106

Rock PL, Roiser JP, Riedel WJ, Blackwell AD (2014) Cognitive impairment in depression: a systematic review and meta-analysis. Psychol Med 44:2029-2040

Rodriguez JJ, Noristani HN, Verkhratsky A (2012) The serotonergic system in ageing and Alzheimer's disease. Prog Neurobiol 99:15-41

Sambeth A, Blokland A, Harmer CJ, Kilkens TOC, Nathan PJ, Porter RJ, Schmitt JAJ, Scholtissen B, Sobczak S, Young AH, Riedel WJ (2007) Sex differences in the effect of acute tryptophan depletion on declarative episodic memory: a pooled analysis of nine studies. Neurosci Biobehav Rev 31:516-529

Sambeth A, Riedel WJ, Tillie DE, Blokland A, Postma A, Schmitt JA (2009) Memory impairments in humans after acute tryptophan depletion using a novel gelatin-based protein drink. J Psychopharmacol 23:56-64

Schwarz S, Froelich L, Burns A (2012) Pharmacological treatment of dementia. Curr Opin Psychiatr 25:542-550 
Seyedabadi M, Fakhfouri G, Ramezani V, Mehr SE, Rahimian R (2014) The role of serotonin in memory: interactions with neurotransmitters and downstream signaling. Exp Brain Res 232:723-738

Sherman SJ, Atri A, Hasselmo ME, Stern CE, Howard MW (2003) Scopolamine impairs human recognition memory: data and modeling. Behav Neurosci 117:526-539

Snyder PJ, Bednar MM, Cromer JR, Maruff P (2005) Reversal of scopolamine-induced deficits with a single dose of donepezil, an acetylcholinesterase inhibitor. Alzheimers Dement 1:126-135

Sperling R, Greve D, Dale A, Killiany R, Holmes J, Rosas HD, Cocchiarella A, Firth P, Rosen B, Lake S, Lange N, Routledge C, Albert M (2002) Functional MRI detection of pharmacologically induced memory impairment. PNAS 99:455-460

Stancampiano R, Cocco S, Cugusi C, Sarais L, Fadda F (1999) Serotonin and acetylcholine release response in the rat hippocampus during a spatial memory task. Neuroscience 89:1135-1143

Steckler T, Sahgal A (1995) The role of serotonergic-cholinergic interactions in the mediation of cognitive behaviour. Behav Brain Res 67: 165-199

Toda N, Kaneko T, Kogen H (2010) Development of an efficient therapeutic agent for Alzheimer's disease: design and synthesis of dual inhibitors of acetylcholinesterase and serotonin transporter. Chem Pharm Bull 58:273-287

Trillo L, Das D, Hsieh W, Medina B, Moghadam S, Lin B, Dang V, Sanchez MM, De Miguel Z, Ashford JW, Salehi A (2013)
Ascending monoaminergic systems alterations in Alzheimer's disease. Translating basic science into clinical care. Neurosci Biobehav Rev 37:1363-1379

Tune L, Carr S, Hoag E, Cooper T (1992) Anticholinergic effects of drugs commonly prescribed for the elderly: potential means for assessing risk of delirium. Am J Psychiatr 149:1393-1394

Van Harten J (1993) Clinical pharmacokinetics of selective serotonin reuptake inhibitors. Clin Pharmacokinet 24:203-220

Van Ruitenbeek P, Vermeeren A, Riedel WJ (2008) Histamine H1receptor blockade in humans affects psychomotor performance but not memory. J Psychopharmacol 22:663-672

Van Strien JW, Verkoeijen PP, Van der Meer N, Franken IH (2007) Electrophysiological correlates of word repetition spacing: ERP and induced band power old/new effects with massed and spaced repetitions. Int J Psychophysiol 66:205-214

Wezenberg E, Verkes RJ, Sabbe BG, Ruigt GS, Hulstijn W (2005) Modulation of memory and visuospatial processes by biperiden and rivastigmine in elderly healthy subjects. Psychopharmacology (Berl) 181:582-594

Woolley ML, Marsden CA, Sleight AJ, Fone KCF (2003) Reversal of a cholinergic-induced deficit in a rodent model of recognition memory by the selective 5-HT6 receptor antagonist, Ro 04-6790. Psychopharmacology (Berl) 170:358-367

Xu Y, Yan J, Zhou P, Li J, Gao H, Xia Y, Wang Q (2012) Neurotransmitter receptors and cognitive dysfunction in Alzheimer's disease and Parkinson's disease. Prog Neurobiol 97:1-13 